\title{
Significados de paternidad para jóvenes universitarios: cotidianidad, relaciones y cambios en proyecto de vida
}

\author{
Andrea Hernández-Quirama, Ph.D. ${ }^{a}$ \\ Universidad Industrial de Santander, Colombia \\ Carolina Rivero-Rubio, Mg. ${ }^{\mathrm{b}}$ \\ Universidad Industrial de Santander, Colombia \\ Johana Linares-García, Mg. ${ }^{c}$ \\ Universidad Industrial de Santander, Colombia
}

\section{Resumen (analítico)}

Las paternidades en universitarios conllevan vulnerabilidades, cambios y dicotomías. Comprender los significados atribuidos a su paternidad implicó basarse en principios del interaccionismo simbólico a partir de la descripción de cotidianidad, relaciones y cambios en su proyecto de vida. La metodología se basó en el enfoque de teoría fundamentada. Se aplicaron entrevistas semiestructuradas a profundidad a ocho estudiantes de pregrado de una universidad pública en Colombia. Ser joven, padre y estudiante implica asumir múltiples actividades que llevan a reducir la paternidad a una responsabilidad predominantemente económica. Generando tensiones en los jóvenes quienes se ven ante la necesidad de intensificar o incursionar en mercados laborales precarizados que afectan la salud mental y física; por ende, repercuten en el rendimiento académico y perpetúan los roles tradicionales atribuidos a los géneros.

Palabras clave

Padres, joven, estudiante, universidad.

Thesauro

Tesauro de Ciencias Sociales de la Unesco.

\section{Para citar este artículo}

Hernández-Quirama, A., Rivero-Rubio, C., \& LinaresGarcía, J. (2021). Significados de paternidad para jóvenes universitarios: cotidianidad, relaciones y cambios en proyecto de vida. Revista Latinoamericana de Ciencias Sociales, Niñez y Juventud, 19(1), 1-21. https://dx.doi.org/10.11600/rlcsnj.19.1.3924

\section{Historial}

Recibido: 04.10.2019

Aceptado: 11.02.2020

Publicado: 16.12 .2020

\section{Información artículo}

Artículo resultado de la investigación Maternidades y paternidades en estudiantes de pregrado de la Universidad Industrial de Santander, año 2016. Financiación interna, código 1876, de la Vicerrectoría de Investigación y Extensión de la Universidad Industrial de Santander. Fecha de inicio abril 29 de 2016 y de finalización abril 28 de 2017. Área: sociología.

Subárea: trabaio social. 
Meanings around paternity for young university students: daily life, relationships and changes in life plans

Abstract (analytical)

Paternities in universities lead to vulnerabilities, changes and dichotomies. Understanding the meanings attributed to fatherhood involves basing this research on the principles of symbolic interactionism based on the description of everyday life, relationships and changes in life plans. The methodology used Grounded Theory approach. In-depth semistructured interviews were conducted with eight undergraduate male students at a public university in Colombia. Being a young person, a father and a student requires carrying out multiple activities that lead to reducing their fatherhood to a predominantly economic responsibility. This created tensions among the young fathers who felt the need to earn more or enter precarious labor markets that affect their mental and physical health, which in turn has an impact on their academic performance and perpetuates traditional roles attributed to genders.

Keywords

Parents, youth, students, university.

\section{Significados da paternidade para jovens universitários: cotidiano, relações e mudanças no projeto de vida}

Resumo (analítico)

As paternidades em universitários levam a vulnerabilidades, mudanças e dicotomias. Entender os significados atribuídos à sua paternidade envolveu contar com princípios do interacionismo simbólico baseado na descrição da vida cotidiana, relacionamentos e mudanças em seu projeto de vida. A metodologia foi baseada na abordagem da teoria fundamentada. Entrevistas semiestruturadas aprofundadas foram aplicadas a oito estudantes de graduação em uma universidade pública na Colômbia. Ser jovem, pai e aluno envolve assumir múltiplas atividades que levam à redução da paternidade à responsabilidade predominantemente econômica, gerando tensões nos jovems que enfrentam a necessidade de intensificar ou entrar nos mercados de trabalho precários que afetam a saúde mental e física, repercutem no desempenho acadêmico e perpetuam papéis tradicionais atribuídos aos gêneros.

Palavras-chave

Pais, joven, estudante, universidade.

Información autoras

[a] Trabajadora Social. Ph.D. en Investigaciones Feministas (Universidad Pablo de Olavide). Profesora de la Universidad Industrial de Santander. (iD) 0000-0003-1955-0566. H5: 4. Correo electrónico:

ahernanq@uis.edu.co

[b] Médica y cirujana. Magíster en Ciencias de la Salud (Universidad de Brasilia). Profesora de la Universidad Industrial de Santander. (iD) 0000-0002-5508-4286. H5: 0. Correo electrónico: carivrub@gmail.com

[c] Trabajadora Social. Magíster en Ordenamiento Territorial (Universidad Santo Tomas). Profesora Universidad Industrial de Santander. (iD) 0000-0001-5401-4633. H5: 3. Correo electrónico: johana.linares.garcia@gmail.com 


\section{Introducción}

os significados construidos alrededor de la paternidad en los jóvenes universiBlumer (1969): primera, «el ser humano orienta sus actos hacia las cosas en función de lo que estas significan para él» (p. 2). En este caso, la cosa es la paternidad, la cual puede abordarse desde el estudio de la cotidianidad; en esta se hace evidente la conducta y los comportamientos del sujeto que, a su vez, dan cuenta de la construcción cultural alrededor de los roles en tensión (ser padre, joven y estudiante), así como de las actividades de economía, cuidado y academia. Segunda, «el significado de estas cosas se deriva de, o surge como consecuencia de la interacción social que cada cual mantiene con su prójimo» (p. 2); es decir, las relaciones del sujeto con su pareja, familiares, compañeros de estudio y amigos, así como con su hijo o hija y consigo mismo en el proceso de ser padre. Y, tercera, «los significados se manipulan y modifican mediante un proceso interpretativo desarrollado por la personas al enfrentarse con las cosas que va hallando a su paso» (p. 3); por lo tanto, es importante considerar que los significados atribuidos a la paternidad son un proceso formativo en donde existe una gran influencia cultural, la cual es un «instrumento para la orientación y formación del acto» (p. 4). Por tal razón, para abordar los significados es necesario indagar en los cambios dado que son resultado de un proceso de autointeracción del individuo.

Durante años, el interés de las investigaciones sobre las transformaciones y los significados que una persona le atribuye al acto de tener un hijo se han centrado especialmente en las experiencias de las mujeres en el embarazo, parto y puerperio. Nieri (2017) destaca cómo las primeras investigaciones sobre la paternidad se centraban en demostrar que la historia del hombre y sus relaciones determinaban la forma de interactuar con el hijo.

La dimensión cultural posee un papel preponderante en torno a la significación de la paternidad, dado que a ella se adscriben funciones y comportamientos acerca de lo 
que se espera de ser padre. Se plantea que existe una carga cultural en donde la imagen de ser padre es sinónimo de proveeduría, la cual es considerada por la sociedad y por ellos mismos como una obligación y una responsabilidad (Lamus \& Useche, 2002).

En un primer momento, la paternidad era abordaba desde el nacimiento; no obstante, con el tiempo se ha venido estudiando como un proceso que inicia desde la gestación. Sin lugar a dudas, la transición hacia la paternidad refleja los cuestionamientos de la sociedad contemporánea alrededor de roles tradicionales, en donde el ser padre se ciñe al rol de proveeduría económica (Puyana \& Mosquera, 2005). En la actualidad, el surgimiento de las nuevas paternidades se debe en gran medida a la deconstrucción de la masculinidad, entendiéndola desde un espectro más amplio y humano. En la bibliografía se observa cómo tan solo a finales de los años noventa se documenta la participación del hombre en el cuidado, el cual ha sido considerado de manera tradicional como un asunto natural del rol materno (Cebotarev, 2003).

Actualmente se presentan cambios en el ejercicio de la paternidad, en especial a nivel generacional. Los padres jóvenes de mayor escolaridad están participando más en la crianza y educación de sus hijos (Fuller, 2000). En esta resignificación se conservan los atributos positivos de la visión tradicional y se incluye el componente afectivo en las representaciones sociales de la paternidad moderna (Gallardo et al., 2006). No obstante, a pesar de la transformación en las relaciones padre-hijo, el reconocimiento en la esfera pública como proveedor económico se halla latente.

Ser padre está determinado por el ciclo vital, la edad, escolaridad y nivel socioeconómico. Por lo tanto, ser padre joven presenta dicotomías, dado que reafirma la hombría adulta y limita el espíritu de libertad, conquista y competencia juveniles; de tal manera, implica cambios en el proyecto de vida, obligando al sujeto a reordenarlo, postergando las expectativas personales y, por ende, generando vulnerabilidades sociales, educativas y económicas (De Martino, 2014).

En la Universidad Industrial de Santander (en adelante UIS) se han consolidado programas de bienestar estudiantil alrededor de la atención integral a la mujer gestante, dejando con ello entrever la preocupación institucional por atender el fenómeno de la maternidad durante el desarrollo del proyecto académico de las jóvenes. Respecto a los hombres jóvenes, los programas sobre la paternidad son escasos. En este sentido, surge el interés de indagar acerca de cuáles son los significados sobre la paternidad que han construido los estudiantes de pregrado de la UIS que tienen hijos o hijas. Para ello, se buscó dar cuenta de la cotidianidad de los actores en la que se desarrollan las actividades de 
economía, cuidado y academia; las relaciones del joven con su pareja, familiares, compañeros de estudio y amigos, así como las relaciones con su hijo o hija y consigo mismo, atendiendo a los cambios que se han presentado en el desarrollo de su proyecto de vida. Lo anterior, siguiendo las orientaciones de Blummer (1969) para comprender los significados que los sujetos le otorgan a la paternidad, sobre todo en una época en donde este rol se halla en constante tensión con los roles de ser joven y estudiante universitario.

Este estudio hace parte del proyecto de investigación titulado «Maternidades y paternidades en estudiantes de pregrado de la Universidad Industrial de Santander, año 2016». Para efectos del presente artículo, se presentan los hallazgos de la construcción del significado de la paternidad.

\section{Método}

Comprender los significados atribuidos a la paternidad para los estudiantes de pregrado de la UIS requirió indagar en sus narrativas acerca de la cotidianidad, las implicaciones de este rol en el estudio, la economía y el cuidado, así como las transformaciones presentadas en sus vidas, teniendo en cuenta las relaciones de este sujeto (figura 1).

\section{Figura 1}

Categorías de análisis para la comprensión de los significados de la paternidad en universitarios

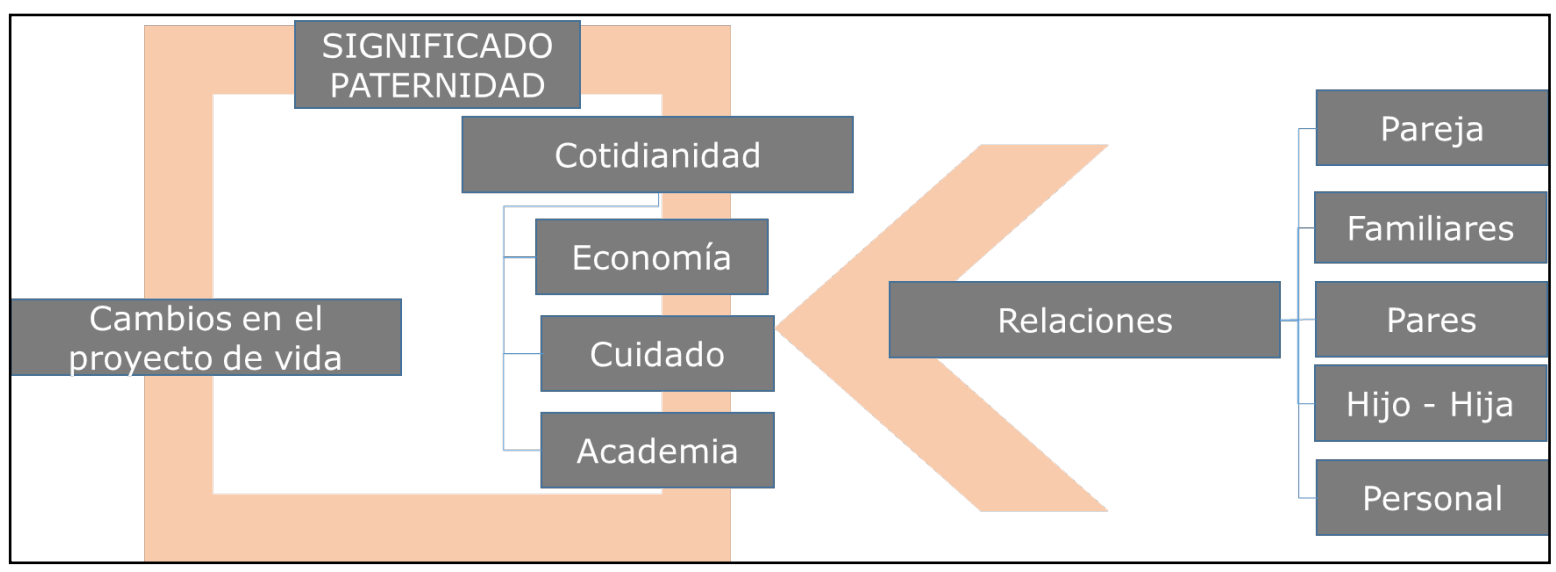

Para tal fin fue necesario abordar el estudio desde el paradigma interpretativo. En particular, el enfoque propuesto por la teoría fundamentada para la comprensión de los significados — cuya base es el interaccionismo simbólico- permite sustentar los conceptos 
emergentes alrededor de la paternidad en los datos para construir teoría sustantiva (Strauss \& Corbin, 2016).

En general, el proceso fue de carácter cíclico e inductivo. Este estuvo dividido de manera general en tres fases: preparatoria, trabajo de campo y analítica (adaptado de Rodríguez et al., 1996). En la fase preparatoria se realizó la reflexión mediante un muestreo teórico de la paternidad, la juventud y la vida académica, así como de los significados para establecer el problema y las categorías deductivas. Esto permitió, entre otras cuestiones, cumplir con el criterio de rigor de transferencia propuesto por Guba y Lincoln (1985), así como diseñar los instrumentos y técnicas de recolección de información.

Para el caso el instrumento de recolección fue la entrevista semiestructurada a profundidad (Valles, 2002). Con base en las categorías analíticas se construyó un guión que permitiera a las entrevistadoras el diálogo fluido con los actores. Así mismo, se construyó una ficha de seguimiento a las respuestas de los participantes para identificar los elementos a profundizar. Durante la fase preparatoria también fue necesario establecer la forma de acceder a la población. El contacto con los actores se realizó mediante el muestreo por cadena o redes (Flick, 2007), dado que la UIS no cuenta con un registro actualizado de los padres vinculados al ámbito universitario. De igual forma, se determinó el lugar de los encuentros, optando por un ambiente no naturalista controlado por el equipo investigador; se establecieron las consideraciones éticas, se diseñó el protocolo de aplicación de la entrevista (en el que se trazaron las reglas para la moderación a fin incitar el diálogo) y se acordaron estrategias de análisis inicial posentrevista para identificar aspectos clave sobre los cuáles profundizar con los actores.

Entre los criterios de selección de la población se determinó que los participantes del estudio debían ser hombres jóvenes padres, es decir, con edades entre los 18 y los 24 años y que, al momento de la entrevista (segundo semestre académico del año 2016) se encontraran vinculados a la universidad como estudiantes activos de los programas de pregrado.

En la fase de trabajo de campo se realizó el acceso a la población de manera progresiva. Se buscó la participación equilibrada de hombres de cada una de las facultades que integran la UIS. Estas agrupan campos y disciplinas afines del conocimiento. Para el caso se logró la vinculación de ocho sujetos, de los cuales dos se encontraban adelantando estudios en la Facultad de Ciencias, dos en la Facultad de Ciencias Humanas, uno en la Facultad de Ingenierías Fisicomecánicas, dos en la Facultad de Ingenierías Fisicoquímicas y uno en la Facultad de Salud. En este punto, es importante destacar que, aunque se buscó 
representatividad de los sujetos por facultad, el interés giró alrededor de la significancia de la muestra, razón por la cual fue necesario seleccionar de cada unidad académica los actores considerados clave para la comprensión de los significados de paternidad.

Durante las entrevistas se leyó el consentimiento informado a los jóvenes, exponiendo los alcances, riesgos y beneficios de su participación en el estudio. El consentimiento fue aprobado por el Comité de Ética de la Universidad en el que se establecen las directrices para la captura, registro y custodia de la información.

A medida que se iba desarrollando la fase de trabajo de campo, el equipo de investigación fue avanzando en la fase de análisis. Para tal fin, fue necesaria la disposición de la información en formato digital mediante transcripciones de las entrevistas. Para garantizar la calidad del proceso se establecieron códigos que permitieron dar cuenta de los gestos y de las entonaciones o expresiones no verbales, dado que también se hallan dotadas de significados. Por tal motivo, fue necesario que cada entrevistador realizara la transcripción del diálogo con el actor clave.

Posteriormente, la información fue organizada y dispuesta para el análisis. Se utilizó como apoyo el software especializado $\mathrm{NVivo}^{\circledR}{ }^{\text {versión }}$ 11. En este punto se buscó la construcción teórica a partir de la descripción de los datos, hasta el ordenamiento conceptual y la teorización, cuestiones que Strauss y Corbin (2016) expresan como el macro análisis y el microanálisis. Para tal fin, fue necesario realizar un proceso de codificación abierta buscando categorías emergentes a partir de las deductivas; de codificación axial, mediante el relacionamiento categorial por la complejidad del significado de la paternidad; y de codificación selectiva, en donde se procuró maximizar las similitudes y reducir las diferencias para la construcción del significado de ser padre, joven y estudiante universitario.

\section{Resultados}

Comprender el significado de la paternidad construido por los jóvenes universitarios se logró mediante el análisis de la cotidianidad en la que, aún hoy, prima la concepción tradicional del rol de ser padre. Esta situación genera tensiones en el joven por la multiplicidad de actividades alrededor de la economía, el cuidado y su desarrollo académicoprofesional. Así mismo, se analizaron las relaciones del joven para dar cuenta de estas actividades y, finalmente, se identificaron los cambios en el proyecto de vida. Estos 
elementos permitieron deducir que la paternidad genera una carga afectiva y económica, en la cual el joven requiere mayor apoyo para lograr equilibrarse.

\section{Cotidianidad, la paternidad que quita el sueño: «A veces no puedo dormir pensando en el niño»}

Asumir el rol paterno es un proceso de transición en el que el hombre joven va orientando sus actos acordes a lo que estos significan para él. El inicio de esta transición se da con la gestación. En todos los casos, esta situación no fue planeada, por lo que se generaron sentimientos de angustia e incertidumbre debido a los cambios que implicaría el nacimiento del hijo (Briones \& González, 2015). Sin embargo, las relaciones del joven con su pareja y el nacimiento del hijo hacen que, con el tiempo, los sentimientos se transformen.

Durante el embarazo, fue con temores; me llamaban personas y decían «¿Qué va a hacer, cómo va a hacer?»; eso le crea a uno como inseguridad y temor. Entonces, y ahora ¿qué voy a hacer? Pero eso se fue mejorando con el tiempo hasta que el niño nació y ya uno pierde el miedo. (Estudiante hombre, Facultad de Ciencias Humanas)

Hacer público el embarazo es un paso clave para asumir la condición procreativa. En general, son los hombres quienes realizan esta tarea. El acto de contar determinará en gran medida las relaciones del joven con su familia y la de su pareja (Escobar, 2012, p. 79). Éste se entiende como un acto de responsabilidad ante la crianza, relacionado de manera directa con la proveeduría económica. En general, la noticia de la paternidad tiende a ser asumida por las familias del joven como un error que debe enfrentarse. Aunque se brindan apoyos necesarios para asumir el nuevo rol, se manifiestan señalamientos que inciden en el estado de ánimo de los jóvenes padres.

Mi papá me dijo y ahora ¿qué vas a hacer? Y yo, responder, qué más toca hacer, responder, yo respondo y ya. (Estudiante hombre, Facultad de Ciencias Humanas)

Cuando les dije fue obviamente un golpe para ellos; me dijeron de todo, que estaban decepcionados, me bajaron la moral. Afortunadamente, después siguieron dándome el apoyo económico, porque es una gran ayuda. Lo duro fue todo lo que me dijeron; están en el derecho de decirme de todo. Fue triste para mi familia. Mi papá asumió un rol machista, usted tiene que trabajar y ya, no puede estudiar ni hacer nada, solamente trabajar por su hijo; usted cometió el error y enfréntelo. (Estudiante hombre, Facultad Fisicomecánicas) 
Tras el acto de hacer pública la responsabilidad paterna se presenta la preocupación en los jóvenes por cubrir las necesidades del hijo y los gastos asociados al embarazo, como los controles de salud. Es así como conseguir ingresos se convierte en un imperativo para los estudiantes (Briones \& González, 2015). Con el embarazo aparecen las primeras responsabilidades de proveeduría, ligadas a las necesidades propias de la etapa de gestación.

Todavía no soy papá; estoy en etapa de gestación, mi novia está en embarazo. Ella tiene que consumir la Ensoy Prenatal ${ }^{\circledR ;}$, hay que comprarla y vale como 49 ooo pesos, dura de 15 a 20 días. (Estudiante hombre, Facultad Fisicoquímicas)

En los jóvenes es más fuerte el discurso de las necesidades económicas de la crianza sobre las afectivas. Estas se reducen al momento del nacimiento y están determinadas por la cercanía con el hijo. En la mayoría de los discursos, cuando se hace el relato de la cotidianidad, aparece la paternidad marcadamente como un evento reflejado en la intensificación de tiempos dedicados a lo laboral. Solo en un discurso emerge la presencia del hijo entendida también como cuidado y protección; lo que se traduce como una perpetuación de los significados atribuidos a los roles tradicionales tanto paternales como maternales. Los hijos se encuentran al cuidado de la madre, mientras el padre garantiza las condiciones económicas para su cuidado. Es así como su jornada se distribuye entre los estudios y el trabajo.

Me levanto a las 5 a. m., me arreglo, tengo clase a las seis de la mañana; apenas salgo de la universidad me voy para el trabajo, tengo que cumplir 40 horas semanales de trabajo. El lunes tengo clase de cinco a siete de la noche, entonces entro a trabajar a las siete y treinta de la mañana, después salgo a las cuatro de la tarde me vengo para la universidad, voy a clase, tengo media hora libre, entonces alcanzo a repasar lo de la clase, luego me regreso nuevamente al trabajo, salgo a las nueve y treinta de la noche de ahí me voy para la casa. La rutina, es lo mismo. (Estudiante hombre, Facultad Fisicoquímicas)

Las responsabilidades económicas de los jóvenes padres incurren en la adopción de roles relacionados con trabajos, que deben compaginarse con los horarios académicos matriculados y las actividades propias de su función paterna. En situaciones extremas de precariedad económica, los estudiantes asumen múltiples compromisos para responder en las dimensiones económica, académica y familiar. Lo que provoca fuertes tensiones en sus vidas. 
Tenía tres trabajos y estudiaba. Solamente venía a la universidad a clase y en la casa llegar en las noches a estudiar lo que pudiera. Trabajar de lunes a lunes desde las cuatro de la mañana; me levantaba para ir al trabajo y salía de uno, me iba a hacer el otro y después salía de ese y me iba a otro, hasta las doce de la noche. Entonces era así el ciclo. Llevo seis años en donde no sé qué es descansar un domingo. (Estudiante hombre, Facultad Fisicomecánicas)

Los primeros tres semestres fue difícil porque a veces no tenía para el almuerzo y me tocaba pasar sin comer. Ella ha probado varios trabajos, se ha quedado sin empleo, tiene deudas, yo tengo deudas, la familia mía y la de ella tiene deudas; entonces estamos ahí tratando de no ahogarnos. (Estudiante hombre, Facultad Fisicomecánicas)

Cotidianidades como las anteriores llevan a que los jóvenes, en ocasiones, reduzcan el significado de la paternidad a la proveeduría económica. Garantizar la economía para el cuidado pareciera un asunto preponderantemente masculino que genera tensiones en los jóvenes. El sujeto se ve en la obligación de anteponer las necesidades del hijo a las propias.

Ser padre es simplemente trabajar para darle lo que el hijo quiere a pesar de que no comparta momentos con él; simplemente es cubrir sus necesidades básicas. (Estudiante hombre, Facultad Fisicomecánicas)

Sé que tengo más gastos de los que tenía programados, sé que ando decaído. Ya no pienso en mí. Ahora tengo más obligaciones; es algo para lo que uno no está preparado, o sea, es muy difícil. (Estudiante hombre, Facultad Fisicoquímicas)

Ahora que tengo a mi hija ya no puedo pensar en diversión, sino lo que tengo es una responsabilidad. (Estudiante hombre, Facultad Fisicomecánicas)

En la paternidad, los hábitos y conductas se transforman. Así mismo, aumenta el autocuidado y la responsabilidad frente a las actividades diarias. Los jóvenes refieren un mejor manejo del tiempo y organización de actividades a realizar.

Uno hace las cosas más responsablemente y con más seguridad. Ya no hago las cosas a medias sino las termino prácticamente en el momento. (Estudiante hombre, Facultad Fisicomecánicas)

A pesar de los esfuerzos del joven por asumir la paternidad sin dejar de lado su desarrollo académico-profesional, la sobrecarga laboral y el mercado precarizado en que se 
insertan, afectan de manera directa su desempeño y retención académica. En algunos casos se ven en la obligación de aplazar el semestre académico.

He tenido pésimas notas este semestre. Ha sido muy duro. Venía bien y de un momento no me concentro muy bien para hacer las cosas; el tiempo es muy escaso para estudiar. A mí me faltan dos semestres. La idea mía es ahorrar, trabajar tiempo completo, poder ahorrar, darle un semestre, parar un semestre, así como ir alternando. (Estudiante hombre, Facultad Fisicoquímicas)

La obligación de mantenimiento económico para su hijo complejiza la capacidad de respuesta de los jóvenes a sus estudios; no pueden rendir igual, pues ya no cuentan con el tiempo suficiente para estudiar. Ahora la prioridad es trabajar pese a que, paradójicamente, también necesitan terminar pronto su carrera.

Antes me iba mejor que ahora. El semestre pasado el niño entró al colegio y eso es caro. Yo me metí a trabajar y no venía a las clases; entonces, pues ha sido complicado, me he bajado mucho académicamente. Ha sido difícil llevar ambas cosas. He estado pensando dejar de estudiar. (Estudiante hombre, Facultad de Ciencias Humanas)

La multiplicidad de tareas del joven ocasiona estrés que afecta de manera directa su estado de salud física y mental. Esto pone a los jóvenes en la dicotomía de decidir si continuar o no sus estudios (Briones \& González, 2015).

En épocas de parciales uno se agobia mucho, pierdo el apetito, me estreso, bajo de peso. Pues estoy cargado de problemas, necesito plata para el colegio del niño, la mamá empieza a agobiarme por plata o que llevo bastante tiempo sin verlo. Se me empieza a llenar la cabeza de esos problemas y estoy estudiando; entonces, tengo un minuto de concentración y dos minutos elevado. Es como una hecatombe de la parte mental. Hasta pensar en dejar todo y huir, no querer más con esto; pero solamente queda seguir, ¿qué más? (Estudiante hombre, Facultad Fisicomecánicas)

Respecto a las afectaciones en la salud mental, en su mayoría se reflejan a través del insomnio, síntomas de ansiedad, depresivos, cansancio mental, pérdida de concentración e inseguridad.

He tenido cambios anímicos de todo tipo. Estoy demasiado estresado. (Estudiante hombre, Facultad Fisicoquímicas) 
En ocasiones estoy impaciente y en otras triste, a veces depresivo, a veces no puedo dormir pensando en el niño, uno se deprime más fácil por lo que a veces no siente apoyo. (Estudiante hombre, Facultad Fisicomecánicas)

Lo anterior conlleva al desarrollo de afecciones en la salud física asociadas a dolores de espalda, dolores de cabeza, pérdida o aumento de peso.

Uno se agobia mucho, se pierde el apetito, se estresa, yo bajo de peso, paso noches sin dormir por estar pensando en los problemas del niño. (Estudiante hombre, Facultad Fisicomecánicas)

He bajado 17 kilos de peso. Ando con dolor de espalda y cabeza pensando. (Estudiante hombre, Facultad Fisicoquímicas)

En síntesis, la cotidianidad del joven universitario que asume la paternidad, se ve fuertemente permeada por las demandas socioculturales del rol paterno tradicional. Aunque los nuevos padres quieran destinar tiempo para el cuidado, el afecto y el fortalecimiento de los vínculos con sus hijos, las cuestiones académicas y económicas limitan la interacción y perpetúan los roles tradicionales del ser padre.

\section{La paternidad: relaciones con el hijo, la pareja,} familia, amigos y académicas

El significado de la paternidad se ve influenciado en los estudiantes por la cercanía o lejanía física que tienen con sus hijos, notándose especialmente afectado en los casos en que esta distancia es mayor. Se percibe una despersonalización de la paternidad que, en algunos casos, es asumida por la figura paterna de la familia de la madre.

Prácticamente yo no tengo comunicación con el niño; el papá es el abuelo [materno], el que más quiere al niño y el que le da casi todo. Se la pasa con él. (Estudiante hombre, Facultad Fisicomecánicas)

El distanciamiento del padre con el hijo le impide asumir los roles del cuidado y participación de la crianza. Esto genera en los jóvenes sentimientos de tristeza ocasionados por la separación, en oposición a la alegría y el orgullo de sentirse padres.

Cuando estoy cerca quisiera estar con mi hijo todo el tiempo. No quisiera alejarme. Cuando me voy en el bus me coge el llanto, uno puede llorar así sea un hombre. La alegría que le 
produce a uno es maravillosa. El hecho de que esté él respondiendo a unos estímulos, eso me hace grande, me siento orgulloso. (Estudiante hombre, Facultad Fisicomecánicas)

El significado de la paternidad también se ve influido por el tipo de relación que se tenga en la actualidad con la madre del hijo; en algunos casos se observó que este tipo de relación se vio afectada por el acompañamiento realizado, o no, durante el periodo del embarazo. En los casos que no se presentó, se llevó a cabo una ruptura con la pareja.

Yo tuve muy poco que ver cuando ella estaba en embarazo; entonces ella siempre se la pasaba brava conmigo. Al principio ella no me dejaba ver el niño; era un problema. (Estudiante hombre, Facultad Fisicomecánicas)

En cuanto a las relaciones familiares, se fortalecen los vínculos. Los jóvenes se ven sostenidos emocionalmente por su red de apoyo familiar, en especial por sus progenitoras, quienes los apoyan para asumir las responsabilidades de la paternidad y continuar con el proyecto educativo.

Mi mamá fue mi apoyo, siempre lo ha sido. Ella me dijo: «No, yo le voy a colaborar en lo que pueda, pero usted tiene que seguir estudiando». (Estudiante hombre, Facultad Fisicomecánicas)

En el ámbito social, los amigos asumen posturas de rechazo hacia el joven por su nueva situación. Las libertades y responsabilidades cambian. Ser padre a esta edad se entiende como una situación que altera la vida del joven.

Creo que para los amigos siempre es chocante porque ellos no se lo esperan; entonces hasta les genera temor. Es como una respuesta cultural de cómo usted siendo joven va a ser papá. Entonces, ya se tiró la vida. (Estudiante hombre, Facultad de Ciencias)

En el ámbito académico, los docentes juegan un rol determinante para el desarrollo de los jóvenes. Los estudiantes refirieron que la mayoría de las respuestas de los docentes ante la nueva paternidad fueron positivas: generaron ambientes de apoyo y comprensión para los estudiantes padres, vislumbrando al nuevo hijo como una motivación; aconsejaron y guiaron la toma de decisiones como, por ejemplo, la de la comunicación de la noticia del embarazo a la familia de la madre; y en ocasiones ejemplificaron la situación con su propia historia personal (la de haber sido padres cursando sus estudios de pregrado). 
Yo dejé de ir a clase y me dijo un profesor «tranquilo, acá no tiene problema». Me colaboró bastante. Me dijo que un hijo no es un impedimento, es una bendición, es para seguir adelante y luchar por ellos. Otro profesor me aconsejó contarles a los papás de mi pareja. Eso sí fue otro obstáculo tenaz. Él me dijo: «Coja el toro por los cuernos, eso qué cuentos, acá ya lo que está pasando es real, no es cualquier cosa». (Estudiante hombre, Facultad Fisicomecánicas)

No obstante, se presentan situaciones de incomprensión por parte de algunos docentes para quienes, por ejemplo, el nacimiento es un asunto que solo le compete a la joven madre. Estas posturas reflejan los imaginarios culturales sobre ser padre, en los que se les excluye del cuidado, acompañamiento y apoyo que inician antes del nacimiento.

Para el tiempo del parto tenía que entregar un trabajo de suma importancia; el caso es que no lo hice por estar acompañándola y no hablé con el profesor. Y un compañero le dijo «Profe es que él no pudo venir porque nació el niño, va a ser papá». Entonces, el profesor dijo: «No, pero la que está teniendo el niño es la mamá». (Estudiante hombre, Facultad Ciencias Humanas)

A pesar del apoyo emocional que algunos docentes brindan a los jóvenes, esto no implica mayores concesiones en el cumplimiento de las actividades académicas.

Uno a veces le dice al profesor que debe ir a trabajar y dice «Eso no es problema mío, usted debe venir el sábado desde las seis hasta las doce del mediodía. Son horarios extracurriculares». Le dicen a uno «Usted está acá para estudiar». Pero yo tengo una obligación. (Estudiante hombre, Facultad Fisicoquímicas)

La paternidad y la ciencia parecen contradictorias para estos jóvenes. La presencialidad y tiempo que demanda la participación en los espacios de formación en investigación les impide vincularse. Aunque existe un apoyo, este no es muy claro para los jóvenes pues ven truncados sus proyectos y experiencias académicas.

La carga era demasiado alta y además nos exigían estar más de doce horas para que el proyecto saliera adelante. Entonces cuando se presentó lo del embarazo yo hablé con mis directores de laboratorio y dijeron apoyarme, pero el apoyo no fue mayor. Tenía una carga muy alta y el estrés porque iba a tener un hijo; sencillamente colapsé. Preferí tirar la mitad de la tesis de grado. Me di cuenta que la investigación muchas veces segrega y que lastimosamente la investigación y la paternidad no congenia del todo en la universidad. (Estudiante hombre, Facultad de Ciencias) 
De lo anterior, se puede afirmar que las relaciones del joven padre determinan el significado de la paternidad. Aunque los jóvenes reciben apoyo de sus parejas, familias y docentes, este es de carácter emocional, no económico, ni de concesión para el desarrollo de ciertas actividades.

\section{La paternidad: cambios en el proyecto de vida}

Como consecuencia de la aparición de los roles de padre y trabajador, sumados al rol de estudiantes, los jóvenes experimentan cambios personales en sus estilos de vida, modificaciones en la organización de su proyecto vital, cambios en sus relaciones de pareja, pérdida de espacios sociales con las amistades previas a su paternidad y reconocimiento social, entre otros.

A nivel académico, los estudiantes padres perciben cambios en la organización de su proyecto de vida, partiendo del hecho de postergar o modificar planes previos a la paternidad que se habían hecho en relación a continuación de estudios de posgrado o de vivir en el exterior.

Teníamos planeado que, apenas termináramos de estudiar, alguno de los dos, o los dos, se iba a ir para el exterior; quizás lo más probable es que ya no ocurra. (Estudiante hombre, Facultad Fisicomecánicas)

Los estudiantes señalan que ya no tienen proyecto de vida propio; ahora todo gira en torno a las necesidades y demandas del hijo, por quien modifican sus planes, costumbres y prioridades.

Ya no tengo ese proyecto de vida. Tenía unas aspiraciones diferentes y ahora ya no. Quería irme del país, estudiar afuera y ahora no, porque hay una responsabilidad. Uno no puede irse y dejar a una criatura. (Estudiante hombre, Facultad Fisicoquímicas)

En el ámbito social, la libertad para disponer del tiempo está condicionada por la paternidad, las obligaciones y responsabilidades que conlleva. En este sentido, la vida social, lúdica y deportiva se ve afectada, pues deben reordenar las actividades diarias en torno a lo que les represente ingresos económicos y a lo académico. La falta de tiempo incide en la disminución de amigos y de espacios de esparcimiento en la universidad; ahora cada minuto cuenta para trabajar o para compartir con el hijo (Briones \& González, 2015). 
Yo no tengo tiempo para nada. El tiempo para mí es muy importante; tengo que aprovecharlo muy bien. (Estudiante hombre, Facultad Fisicoquímicas)

Para los jóvenes es claro cómo la reorganización del tiempo alrededor de la economía y la academia los lleva a repensar las prioridades. En ocasiones se abandonan espacios de desarrollo deportivo.

Yo practicaba un deporte de competición. Cuando ella quedó embarazada, en ese momento mi sueño era ir a los Juegos Olímpicos; estaba haciendo todo lo que estaba en mis manos para empezar a clasificar a los nacionales y hacer parte de la selección. Tenía muy buen rendimiento. Un compañero con el cual entrenábamos fue a los Juegos Olímpicos de Londres 2012 y pues yo aquí. Entonces fue un cambio brutal. (Estudiante hombre, Facultad Fisicomecánicas)

Indudablemente, la paternidad para los jóvenes estudiantes representa modificaciones en sus vidas, sus anhelos y sueños (Duarte, 2016). Estos se ven reorientados para atender las demandas que implican el cuidado del hijo.

\section{Discusión}

La experiencia de la paternidad en los jóvenes universitarios complejiza su momento vital. Hacer frente a un evento no planeado implica asumir una madurez de manera súbita en los ámbitos económico y afectivo, propios de la edad adulta (Cruzat \& Aracena, 2006). Se manifiesta una sensación de pérdida, donde se coarta la libertad del manejo del tiempo. Las actividades y las prioridades se transforman y se focalizan en función del hijo (Alverdi \& Escario, 2007).

La paternidad demanda transitar a una etapa de seriedad y responsabilidad, la cual está estrechamente relacionada con la idea tradicional de proveedor económico, de figura protectora y de jefe del hogar (Izquierdo-Sánchez \& Ferrer-Ribot, 2018). Se presenta, entonces, como una fase en la que se espera de los jóvenes el desempeño de un rol predeterminado socialmente (De Jesús-Reyes \& Cabello-Garza, 2011).

Las tensiones que vive el joven padre responden a la fricción entre las determinaciones sociales, culturales y económicas propias de estas sociedades fuertemente patriarcales sobre el deber ser del rol paterno y el deber ser del rol de estudiante, generando así 
mayores niveles de vulnerabilidad en términos sociales, educativos y económicos (De Martino, 2014).

Es así que el ejercicio de la paternidad a edades tempranas debe analizarse como una situación que aumenta el nivel de vulnerabilidad social, educativa y económica; en especial en el contexto latinoamericano en donde existe una compleja trama de desigualdad, lo que determina condiciones de pobreza (De Martino, 2014). La preponderancia de las obligaciones económicas influye en la valoración social del estudiante padre, cuyo desempeño se tasa en relación a sus ingresos y al tiempo invertido en horas de trabajo para la manutención familiar. Esta situación perpetúa el imaginario hegemónico de masculinidad (Urbina, 2016). Varios estudios asocian la paternidad con la economía, educación y edad del sujeto. Las cuestiones económicas que plantean la necesidad de trabajar para proveer son abordadas en los estudios de Filgueiras et al. (2006), Antunes et al. (2012) y Briones y González (2015).

Así mismo, se entiende que el nivel educativo del hombre influye en la experiencia y significado de la paternidad. Según el orden cultural establecido, los jóvenes deben desarrollar un proyecto de educación superior. Sin embargo, al adquirir la categoría de padres, esta apuesta se halla en riesgo por las necesidades económicas a las que se enfrentan. Lograr concretar el proyecto educativo de los padres jóvenes dependerá en gran medida del ámbito familiar, académico y social en el que se desarrollan. Así, la madre, el padre y los hermanos del joven padre, al igual que los docentes, compañeros y pares, influirán en la experiencia del joven y en el desempeño exitoso de ambos roles (Anabalón et al., 2011). En este sentido, se espera ante la paternidad una reacción positiva como factor social de apoyo, en especial de la familia de origen en la que el joven busca afecto y compresión (Rodríguez, 2009).

En el contexto colombiano contemporáneo la paternidad ha sido estudiada desde los problemas que genera a los jóvenes asumir este nuevo rol. Se percibe como un acontecimiento que condiciona el proyecto de vida del estudiante, pues lo reorienta a la gestión de recursos económicos para la subsistencia y proveeduría. Los imaginarios del rol paterno como proveedor cuestionan al joven sobre su capacidad para desempeñarlo con éxito, pues debe hacerse cargo, no solo del hijo, sino de la madre adolescente, sin haber adquirido independencia económica (Botero \& Castrillón, 2015). Es así como pervive el asocio de la paternidad a la proveeduría económica para la manutención familiar, el cuidado y la crianza de los hijos, lo que implica un considerable porcentaje de los ingresos familiares (Hernández \& Rojas, 2018). 
Por la incertidumbre que genera el futuro del inesperado padre, emergen sentimientos de temor y ansiedad. El joven generalmente demanda apoyo de su contexto para desempeñar su rol paterno, desde comunicar la noticia a las familias, la proveeduría y el cuidado del hijo (Escobar, 2012). La paternidad implica redireccionar su proyecto de vida y reestructurar sus aspiraciones, metas y sueños (Duarte, 2016). Se presentan cambios en su esfera social, que se reduce como resultado de los nuevos roles de padre o trabajador, los cuales restringen el tiempo disponible para compartir y salir con amigos y conocidos.

Es necesario mencionar que, a pesar de la tradición patriarcal, se avanza en la configuración de nuevas paternidades que develan que el cuidado, el amor y las labores domésticas no corresponden únicamente al espacio de lo femenino (Palomar, 2007). Por ende, hoy se demanda mayor reflexión en torno a los significados atribuidos a la paternidad, cada vez más cambiante. En un estudio realizado que difiere a los hallazgos del presente, los hombres jóvenes exigen mayor participación en la crianza y la educación de sus hijos, así como tener relaciones afectivas más cercanas (Viveros, 200o).

En síntesis, la paternidad en la juventud ha sido categorizada como un problema para el individuo que se ve enfrentado a las demandas del rol paterno, generalmente asociadas con la responsabilidad económica. Con ello se demuestra que, a pesar de la reflexión hacia las nuevas masculinidades y los avances en su resignificación, el rol paterno es la expresión de una cultura patriarcal hegemónica que acentúa las relaciones de género desiguales, como resultado de la multiplicidad de actividades alrededor de la proveeduría económica y la academia.

Aunque en el mundo contemporáneo han emergido nuevas paternidades, los roles tradicionales atribuidos a los géneros perpetúan una sobrecarga económica asignada principalmente a los hombres. Esta es culturalmente invisibilizada y afecta su salud física y mental pues, generalmente, deben desempeñarse en trabajos precarizados que se caracterizan por altas jornadas laborales y baja remuneración. Inevitablemente el ejercicio de la paternidad, en el contexto universitario, afecta el rendimiento académico y pone en riesgo el proyecto de vida emprendido por los jóvenes.

Así mismo, las demandas económicas a los hombres median las relaciones afectivas con los hijos. Aún hoy las paternidades se significan alrededor de la satisfacción de necesidades básicas de tipo material. Aunque los jóvenes buscan mayor participación en el ejercicio de la crianza, su cotidianidad se debate entre la proveeduría y la academia, reduciendo por ende el tiempo para el fortalecimiento de los vínculos afectivos en las nuevas familias. 
Las relaciones con la pareja, la familia, el contexto educativo y laboral determinan el ejercicio de nuevas paternidades. El apoyo que reciba el joven para construir una relación afectiva con los hijos dependerá de las interacciones con sus redes familiares y sociales, así como de los cambios que el joven haya tenido que realizar en la organización de su proyecto de vida.

Las transformaciones en las relaciones sociales de los jóvenes responden, en gran medida, a los significados culturales tradicionales atribuidos a la paternidad, que se hallan en contradicción con el desarrollo de la juventud. Ser padre implica una madurez y estabilidad emocional propias de la edad adulta que los jóvenes deben adquirir en un corto periodo de tiempo.

Permanecer en el sistema educativo es un reto para estos jóvenes. Al asumir la proveeduría económica sus relaciones académicas se ven menguadas, así como la posibilidad de centrarse en su proyecto profesional. A pesar de las demandas sociales en torno a la responsabilidad en la crianza existen menos concesiones hacia los hombres para el fortalecimiento de los vínculos afectivos con sus hijos. Es importante profundizar en futuros estudios sobre la construcción de vínculos afectivos del padre con el hijo en contextos complejos en donde se entrecruzan la juventud, academia y paternidad.

\section{Referencias}

Alverdi, I., \& Escario, P. (2007). Los hombres jóvenes y la paternidad. Fundación BBVA. Anabalón, C., Cares, F., Cortés, R., \& Zamora, M. (2011). Construcción de la propia paternidad en adolescentes varones pertenecientes a liceos municipales de la comuna de La Cisterna. Revista de Psicología, 20(1), 53-71. https://doi.org/fngz

Antunes, E., Pereira, L., \& Ferreira, D. (2012). Los significados de la paternidad para los hombres jóvenes en los alrededores de São Paulo-Brasil. Cultura de los Cuidados, 16(33), 55-66. https://doi.org/10.7184/cuid.2012.33.08

Blumer, H. (1969). El interaccionismo simbólico: perspectiva y método. Hora.

Botero, L., \& Castrillón, L. (2015). La experiencia de la paternidad en adolescentes. Revista Virtual Universidad Católica del Norte, (46), 89-101.

Briones, V., \& González, J. (2015). Estudio exploratorio de paternidad en padres universitarios de la Pontificia Universidad Católica de Valparaíso. Pontificia Universidad Católica de Valparaíso. 
Cebotarev, N. (2003). Familia, socialización y nueva paternidad. Revista Latinoamericana de Ciencias Sociales, Niñez y Juventud, 1(2), 5-18.

Cruzat, C., \& Aracena, M. (2006). Significado de la paternidad en adolescentes varones del sector sur-oriente de Santiago. Psykhe, 15(1), 29-44. http://dx.doi.org/10.4067/ So718-22282006000100003

De Jesús-Reyes, D., \& Cabello-Garza, M. L. (2011). Paternidad adolescente y transición a la adultez: una mirada cualitativa en un contexto de marginación social. Iberofórum. Revista de Ciencias Sociales de la Universidad Iberoamericana, 6(11), 1-27.

De Martino, M. (2014). Visibilizando la paternidad adolescente. Prisma Social, (13), 924-943.

Duarte, M. (2016). Embarazo y paternidad juvenil en el departamento del Cesar: iy dónde está el padre? Revista Colombiana de Ciencias Sociales, 7(2), 425-447. https://doi.org/ 10.21501/22161201.1808

Escobar, J. D. (2012). La experiencia de la procreación en adolescentes varones de la ciudad de Medellín. Revista de Psicología. Universidad de Antioquia, 4(1), 75-85.

Filgueiras, M., Galvao, K., Perucchi, J., Beiras, A., \& Tagliamento, G. (2006). Paternidad y juventud: investigando el universo de estratos populares en el sur de Brasil. La Ventana. Revista de estudios de género, 3(23), 213-236.

Flick, U. (2007). Introducción a la investigación cualitativa. Morata.

Fuller, N. (200o). Significados y prácticas de paternidad entre varones urbanos del Perú. En N. Fuller (Ed.), Paternidades en América Latina (pp. 35-89). Fondo Editorial de la Pontificia Universidad Católica del Perú.

Gallardo, G., Gómez, E., Muñoz, M., \& Suárez, N. (2006). Paternidad: representaciones sociales en jóvenes varones heterosexuales universitarios sin hijos. Psykhe, 15(2), 105-116. https://doi.org/10.4067/so718-22282006000200010

Guba, E., \& Lincoln, Y. (1985). Naturalistic inquiry. Sage.

Hernández, A., \& Rojas, H. (2018). El mercado del cuidado, el cuidado del mercado de la niñez en perspectiva de los cuidadores. Saber, Ciencia y Libertad, 13(2), 21-32. https://doi.org/10.18041/2382-3240/saber.2018v13n2.4633

Izquierdo-Sánchez, L., \& Ferrer-Ribot, M. (2018). Las experiencias del padre en las Ucin: una revisión desde la perspectiva de género. Revista Latinoamericana de Ciencias Sociales, Niñez y Juventud, 16(1) 55-69. https://doi.org/10.1160o/1692715x.16102

Lamus, D., \& Useche, X. (2002). Maternidad y paternidad: tradición y cambio en Bucaramanga. Editorial UNAB.

Nieri, L. (2017). Transición y construcción de la paternidad. Interdisciplinaria, 34(2), 425-440. https://doi.org/10.16888/interd.2017.34.2.11 
Palomar, C. (2007). La maternidad ejercida por varones. Debate Feminista, 35, 195-226. https://doi.org/10.22201/cieg.2594066xe.2007.35.1333

Puyana, Y., \& Mosquera, C. (2005). Traer hijos o hijas al mundo: significados culturales de la paternidad y la maternidad. Revista Latinoamericana de Ciencias Sociales, Niñez y Juventud, 3(2), 2-21.

Rodríguez, E. (2009). La paternidad en el adolescente: un problema social. Archivos Venezolanos de Puericultura y Pediatría, 72(3), 86-91.

Rodríguez, G., Gil, J., \& García, E. (1996). Metodología de la investigación cualitativa. Algibe.

Strauss, A., \& Corbin, J. (2016). Bases de la investigación cualitativa: técnicas y procedimientos para desarrollar la teoría fundamentada. Universidad de Antioquia.

Urbina, F. (2016). Paternidades, crianza y cuidado infantil en los discursos de jóvenes varones en ciudad Juárez, Chihuahua. Revista Noesis, 25(50-1), 119-142. https:// doi.org/10.20983/noesis.2016.21.6

Valles, M. (2002). Entrevistas cualitativas. Centro de Investigaciones Sociológicas.

Viveros, M. (2000). Paternidades y masculinidades en el contexto colombiano contemporáneo: perspectivas teóricas y analíticas. En N. Fuller (Ed.), Paternidades en América Latina (pp. 91-127). Pontificia Universidad Católica del Perú. 